University of Nebraska - Lincoln

DigitalCommons@University of Nebraska - Lincoln

Publications of the University of Nebraska

Public Policy Center

Public Policy Center, University of Nebraska

$1-1-2016$

\title{
Agency Theory: Toward a Framework for Research in the Public's Support for and Understanding of Science
}

\author{
Peter Muhlberger \\ University of Nebraska, peterm@unl.edu \\ Lisa M. PytlikZillig \\ University of Nebraska, Ipytlikz@nebraska.edu
}

Follow this and additional works at: https://digitalcommons.unl.edu/publicpolicypublications

Muhlberger, Peter and PytlikZillig, Lisa M., "Agency Theory: Toward a Framework for Research in the Public's Support for and Understanding of Science" (2016). Publications of the University of Nebraska Public Policy Center. 182.

https://digitalcommons.unl.edu/publicpolicypublications/182

This Article is brought to you for free and open access by the Public Policy Center, University of Nebraska at DigitalCommons@University of Nebraska - Lincoln. It has been accepted for inclusion in Publications of the University of Nebraska Public Policy Center by an authorized administrator of DigitalCommons@University of Nebraska - Lincoln. 


\section{IOWA STATE UNIVERSITY \\ Digital Repository}

Iowa State University Summer Symposium on

Science Communication

2016: Confronting the challenges of public participation in environmental, planning and health

decision-making

Jan 1st, 12:00 AM

\section{Agency Theory: Toward a Framework for Research in the Public's Support for and Understanding of Science}

Peter Muhlberger

University of Nebraska-Lincoln, pmuhl1848@gmail.com

Lisa Pytlik-Zillig

University of Nebraska-Lincoln, lpytlikz@nebraska.edu

Follow this and additional works at: https://lib.dr.iastate.edu/sciencecommunication

Part of the Speech and Rhetorical Studies Commons

Muhlberger, Peter and Pytlik-Zillig, Lisa (2016). Agency Theory: Toward a Framework for Research in the Public's Support for and Understanding of Science. Jean Goodwin (Ed.), Confronting the Challenges of Public Participation in Environmental, Planning, and Health Decision-Making. https://doi.org/10.31274/sciencecommunication-180809-10

This Event is brought to you for free and open access by the Conferences and Symposia at Iowa State University Digital Repository. It has been accepted for inclusion in Iowa State University Summer Symposium on Science Communication by an authorized administrator of Iowa State University Digital Repository. For more information, please contact digirep@iastate.edu. 


\title{
Agency Theory: Toward a Framework for Research in the Public's Support for and Understanding of Science
}

\section{PETER MUHLBERGER \& LISA PYTLIK-ZILLIG}

\author{
Public Policy Center \\ University of Nebraska at Lincoln \\ 215 Centennial Mall South, Suite 401 \\ Lincoln, NE 68588-0228 \\ pmuhL1848@gmail.com \\ lpytlikz@nebraska.edu
}

\begin{abstract}
Public understanding of science and public engagement around science policy issues takes place within a complex system involving public opinion, values, identities, social groups, media, and social, economic, and political structures and influences. This paper offers a theory of agency that bridges the psychological and sociological and thereby offers a theoretical framework for understanding the system underlying public understanding of science, support for science, and the implications of public engagement. Agency theory integrates elements of well-established social science theories into an understanding of human agency. Strategies for improved public engagement are discussed.
\end{abstract}

KEYWORDS: agency theory, identity, media, public engagement, public opinion, public understanding of science, science policy, social structure, systems theory, values

\section{INTRODUCTION}

Public attitudes toward and understanding of science are the result of processes both at the level of individual psychology and social structure. Existing social sciences and social science theories, however, tend to focus on one or the other of these possibilities. This suggests that the study of the public understanding of science would benefit from a theory that allows a clear picture of both psychological and sociological processes and their relationships. In addition, many existing social science theories either assume people are guided by strong forms of rationality or are at the mercy of various non-rational causal mechanisms. The study of the public understanding of science would benefit from a theoretical approach that can clarify the evident irrationalities of much public opinion but allow for the possibility of people engaging more rationally with science under good conditions. Without the possibility of rational engagement, the study of the public understanding of science would offer only a dismal picture of the public, one at odds with the presumptive rationality of science itself, and little hope for meaningful public engagement. This paper offers a theory of agency that bridges the psychological and the sociological as well as the rational and irrational. The theory is applied to public understanding of and trust in science and to public engagement on science policy issues. Potential research areas and hypotheses are proposed.

\section{AGENCY THEORY}

Muhlberger, Peter \& Pytlik-Zillig, Lisa. (2016). Agency Theory: Toward a Framework for Research in the Public's Support for and Understanding of Science. In Jean Goodwin (Ed.), Confronting the Challenges of Public Participation: Issues in Environmental, Planning and Health Decision-Making (pp. 109-136). Charleston, SC: CreateSpace. Copyright (C) 2016 the author(s). 
Agency is the exercise of choice in thought and behavior. A theory of agency needs to explain what "choice" is and how choice is exercised or fails to be exercised. Theories of agency are plentiful, both in everyday life and the social sciences, albeit not necessarily explicitly stated. When people say that a person can change their way of life, for example from alcoholism to abstinence, by following certain steps, they are implying a theory of agency.

When psychologists assert that people's decisions and thoughts are subject to systematic departures from rationality (Kahneman, Slovic, \& Tversky, 1982) or to group pressures (Mendelberg, 2002), they imply that people have a lack of free choice. With the current mountain of such psychologically deterministic findings, it is tempting to infer that people do not exercise choice. When other psychologists suggest that people do what they do because they are politically astute actors (Lerner \& Tetlock, 1999) or because they are managing the conception of their own efficacy (Bandura, 2001), this implies forms of rational agency.

Many rational choice theorists and economists offer or imply another theory of agency when they assert that behavior can be explained by people's actions to maximize the fulfillment of their preferences (Elster, 1986). Preferences are understood as unchangeable and not socially influenced and as fully weighed relative to each other. Actions are always instrumental - that is, taken to alter states of the (external) world. This conception of agency does not allow for expressive as opposed to instrumental action (Abelson, 1995), preferences that change or are socially influenced, people to have trouble weighing between different preferences, or people to be unable to maximize their preferences (Simon, 1969).

This paper invokes a theory of agency that the authors will simply call "agency theory." It attempts to discern a plausible understanding of human agency by synthesizing aspects of Carver and Scheier's (Carver \& Scheier, 1981, 1999) self-regulation theory, aspects of adaptive complex systems theory (Mobus \& Kalton, 2015), self-determination theory (Ryan, 2000), social identity theory (Hogg, 1996) Mead's psychology (Mead, 1962), action identification theory (Vallacher \& Wegner, 2000), and other sources. Agency theory seeks a middle path between psychological determinism and the constrained free choice of rational choice theory. It allows for and explains both highly determined choices and "free" choices in thought and behavior, and it seeks to understand the conditions under which choices are free. It also allows for expressive behavior, social influence, and uncertainty over values. It also, as explained below, bridges both psychological and social-structural explanations.

\subsection{Complex Adaptive Systems}

Agency theory begins with the view that people and societies are complex adaptive systems that are subject to the constraints and features of such systems, wherever they are found-in biology, software code, people, or societies. Adaptive systems take in information from their environments and adjust their responses to the environment to better achieve their internal goals. One key feature is feedback loops. In response to a complex, ever-changing environment that is impossible to predict precisely, it is most adaptive for a system to set goals and continually adjust its behavior and, at times, its goals, in response to new information from the environment. The environment, in turn, responds to the system's behavior, thus completing a feedback loop. Another system property implied by feedback loops is equilibrium, which occurs when the system is achieving its goals and does not need to adjust its outputs. Prolonged equilibrium may be rare. 
Another key feature of complex adaptive systems is modularity. The processes involved in transforming environmental inputs into effective adaptive behaviors are extremely complex. Wherever systems are found, this complexity is managed be subdividing the needed processes into relatively discrete functional units or modules, each of which can complete some small task and be reused for different purposes ('reuse' is an important property of modules). Modules take input and reliably give certain outputs without the larger system having to keep track of what goes on in the module - a property called 'encapsulation.' In encapsulation, the components and transformations of information in the module are hidden from the larger system, which only needs to be aware of what inputs a module takes and what kinds of outputs it generates from these inputs.

Without modularity, complex adaptive systems may well be impossible. A programmer seeking to write software with hundreds of thousands of lines of code without modules (and thereby separated namespaces) would be faced with a virtually impossible problem - trying to keep all the variables in mind and all the uses and transformations of these variables in mind so that the next line of code will not in some way have disastrous consequences for something else the software needs to do. Looked at another way, the number of possible interactions of variables or of transformations of variables rises exponentially with the number of these variables and transformations. Encapsulated modules isolate variables and transformations from the same in other modules, thereby vastly reducing the complexity of writing another line of good code. What holds for software also holds for biological systems. Organisms are organized into encapsulated modules: DNA (in part organized into modules called genes) and other cell components, cells, organs, organ systems, social groups, and societies. It is far easier for evolution to create viable organisms when the search space for its genetic algorithm is vastly reduced by modularity and the possibility of gene reuse.

Another key property of complex adaptive systems is 'nesting.' The nesting of modules builds complexity with nested hierarchies of modules. Consider a person driving down a street. At a basic level, this involves the working of individual neurons. Many of the neurons involved are in the cerebellum and are organized into complex modules that control motor action-that is, they coordinate the firing of myriads of muscle groups into complex behaviors that allow a person to steer a car. The complexity of this might be made clear imagining the trouble a toddler would have driving a car, even if the car were the right size and the toddler was determined to drive down the street. The motor cortex's actions are further controlled by modules of neurons in other parts of the brain that advise the motor cortex to stay between the lines on the road and obey a multitude of other traffic rules, using various feedback loops. Beyond this, other parts of the brain are regulating goal-directed activity, such as getting to a meeting on time and going to, say, a political meeting in order to enact the driver's identity as a Democrat or Republican - also all regulated with feedback loops. Moving from the individual driver to social groups and society, the meeting is organized by people with certain identities and understandings who are seeking to replicate certain social structures that legitimize and otherwise further the objectives of a political party, which is itself nested in larger social structures such as nation, government, and a 'public.' Thus, driving down the street can be viewed as an activity in which a multiplicity of nested modules are involved, from neurons and below, to identities, to nations.

An important further property of most complex adaptive systems is emergence-the development of properties based on the interactions of modules that are hard to imagine from the isolated operation of modules. It is difficult to imagine identities and nations from a close 
examination of the functioning of individual neurons. A final important system property is subsumption. In subsumption, higher levels of nested hierarchies of modules need have little involvement in or knowledge of lower levels of nested modules. Conscious attention need have no knowledge of the organization of motor functions or of muscle groups in the execution of motor skills. Consciousness simply wills that a certain action be undertaken, and it is (for now ignoring training of behaviors). Part of this lack of knowledge is due to encapsulation, but another part is that consciousness need not even be aware of the inputs and outputs of lowerlevel modules, something handled by intermediate modules.

\subsection{People as Complex Adaptive Agents}

One of the most important emergent properties for understanding social phenomena is reflexivity, which depends on yet other important emergent properties, such as consciousness and self-awareness. People are, to varying degrees, capable of modifying their own systems, both individual and social-including goals and modules. The first step in reflexivity is building a model of the system, which people do through language that describes the system and its functioning. Language and the reasoning it makes possible then utilize this model to identify limitations and problems with the system and pathways to fixing these issues. For example, someone learning to dance seeks to describe what they are doing wrong and then repeatedly practices the movement paying conscious attention to fixing small aspects of their movement until the whole works and is made automatic. In effect, they are programming their motor cortex with a model and conscious attention. Notice that it is hard work for conscious attention to modify even small movement sequences.

Several important propositions in agency theory stem from this analysis. In agency theory, model building and effortful conscious behavioral change encompasses everything from changing dance steps to changing identities and social arrangements. Behavior here is construed broadly and can include thought patterns such as values, attitudes, and emotions as well as physical actions. A second key point is that conscious attention is highly limited, a point also made in dual-processing theories (Chaiken \& Trope, 1999). The vast majority of human behavior depends on automated modules and processes, with conscious attention utilized either as high level director - making sure that actions are unfolding as it plans, goals are being achieved, and the right general modules are being activated in the right sequence-or as an effortful reprogrammer of errant or new modules. This does not mean that behavior is outside conscious control, but that such control typically requires the agent to have been thoughtfully involved in programming behavioral modules.

On the other hand, it is also not the case that behavioral modules are necessarily programmed with a high degree of reflexivity. People have limited life spans, likely much more limited in the evolutionary past than today, and need to adapt to complex social arrangements. Moreover, to the extent that survival for people is group survival, survival and, therefore, the perpetuation of one's genes, is enhanced by rapid adaptation of people to their social groups so they can play useful roles that benefit the group. Unsurprisingly, then, children rapidly absorb social roles and identities and the associated norms and behaviors through modeling behavior on observation of others (Bandura, 1976) and play in which children practice roles and identities (Mead, 1962). Something as simple as mimicry of roles internalizes behaviors that imply certain ideas and attitudes toward others. Children play acting parental roles in a sexist society internalize behaviors that, if not later corrected, will replicate 
sexism. Moreover, if these roles are later examined, sexist assumptions will, on less than very thorough consideration, seem natural and obvious because these ideas are implied by behavioral patterns that appear to have always existed in the person. Mimicry programs roles and identities largely without reflexivity, both because children do not have well-developed models of self or society to critically reflect on what they are absorbing and because mimicry substantially sidesteps critical processes. Also, the realities of encapsulation and subsumption within self-constructs work to erase the memory of how identities and roles were internalized.

Adaptive systems have goals, and for people the goals generally are part of roles and identities. These can be thought of in several ways. Roles and identities can be viewed as modules that contain organized collections of interrelated goals (or norms), emotional predispositions towards goals and goal attainment, understandings regarding when particular goals apply and for what purposes, and behavioral scripts for achieving the goals. People generally do not have a single role or identity, but a multiplicity. They activate those roles and identities that seem relevant to their current contexts, to address difficulties with execution of identities or roles in the current context by switching to alternatives, or to achieve consistency with some general sense of self. Identity might also be viewed as that which gives a person continuity over time, through varying experiences and changing environments, by offering abstract goals that can be consistently pursued through changing circumstances.

Given, however, that people have multiple identities triggered in part by context, such identities at best offer fragments of consistency. It is necessary to stipulate a "self" that involves more abstract goals that can lend coherence to the multiplicity of identities and role choices. The self necessarily requires a high degree of reflexivity in which a person critically reflects on identities and roles and selects and modifies these into a consistent whole. The extent to which people have such a self may vary. Identities and roles differ, albeit with fuzzy boundaries, in that identities help define what people are while roles, adopted for specific social tasks, only define what people do. This distinction is not critical to what follows and will therefore be collapsed into the term "identity." The cognitive structure and functioning of identities is an area for further development in agency theory and may benefit from insights from role theory, identity control theory (Burke, 2006; Stryker \& Burke, 2000), and coherentist models of cognition (Thagard, 2000; Thagard \& Kroon, 2006).

Importantly, identities can consist of two components-automated processes and linguistic models of the identities. Given how identities are absorbed from the social environment, their linguistic models can be quite underdeveloped relative to what the automated processes contain. Through self-development, people develop improved models of their identities, are better able to correct these identities and make them consistent with each other in the process of developing a self, and develop a critical capacity with respect to their identities. People may be unsure of what actually is in the body of automated processes that constitute their identities and how these diverge from their linguistic model of self. Thus, people might consider themselves brave, but whether they are brave will depend on how they act under duress, based on automated processes. This uncertainty about identity and the dependence of identity on action rather than simply thought, detailed in self-perception theory and self-affirmation theory (Bem, 1967; Steele, 1988), gives rise to the need for expressive behavior-behavior undertaken to exercise a desired identity and not to change the state of the external world.

It is now possible to offer a more sophisticated definition of agency. Agency is the capacity of people to choose and successfully execute goal-directed actions on behalf of a well- 
developed self or reflexively-chosen identities. This is a matter of degree-people have greater agency to the extent that their actions are steered by more reflexively chosen identities or, better still, a well-developed self. Many people, perhaps most, fall far short of being full agents. As indicated in Kantian (Kant, 1974) and more modern ethical theories (Gewirth, 1978), a good society and ethics require respect for people's agency. Given the dependence of people's agency on self-development and social structural conditions that affect such development (Bowles \& Gintis, 1986), ethics requires the furtherance of that agency.

\subsection{Social Identity, Social Structure and Collective Intelligence}

People do develop individual identities grounded in their needs and desires-identities that can be contrary to the demands of their society. Nevertheless, most of the identities children adopt are absorbed from society and are social identities, not identities that focus on individuality. People are not merely capable of being social, they are in part socially constituted, albeit they also carry at least the possibility of individualistic divergence from social identities and prescriptions because they have individual identities and are capable of being agents. Nevertheless, as Durkheim suggests (Durkheim, 1952), many identities stressing seeming "individuality" may actually be social in origins, socially defined, and functional for modern societies.

Because of the social constitution of people, all aspects of social identity and selfcategorization theories (Hogg, 1996; Hogg \& Abrams, 1999) are applicable. Some relevant findings in research on these theories include that people are highly sensitive to social status, choose their identity in a given context so as to enhance that status relative to people in other groups, and selectively attend to, process, and remember information in a biased fashion to promote the status of their group and, thereby, themselves. Social identity theory was, in part, developed to help understand the racial hatred that led to the Holocaust. It is also, however, possible in agency theory for people's development to reach a point at which social identity biases are limited, though this may not describe most people.

Social structural factors, particularly social structural demand, influence the development of an integrated self and of reflexivity. People are complex adaptive systems - if their current poorly integrated selection of identities is sufficient to achieve internal goals given environmental conditions, they are adequately adapted and there is no external pressure for them to pursue further self-development. The social environment can play several roles here. It can make goals easy to reach, but it can also disseminate identities with easy to reach goals. The belief systems the environment disseminates regarding authority, personal worth, and what is valuable also shape which identities are attractive. Finally, the mix of identities that are frequently triggered by the environment may be those with easy to reach goals. This can involve the environment steering attention, which selects the current active identity or role, away from some identities and toward others. The environment can also tie up attention resources so a person is too preoccupied to notice inconsistencies among identities or devote the effort needed to correct such inconsistencies. An important feature of social structure is how it systematically directs or redirects people's limited attention resources. The economy of attention is appreciably socially structured, including the structure of communication-the people, organizations, and communications with which people are likely to interact or to which they are likely to be exposed. Another way of looking at the influence of the social 
environment is that people generally become what is demanded of them by their society (Bowles \& Gintis, 1986).

Some people, however, are less susceptible to social structural shaping than others. People can diverge from social structural constraints through intellectual curiosity and honesty. A person high in need for cognition (Cacioppo, Petty, Feinstein, \& Jarvis, 1996) and low in motivated reasoning will be more aware of and willing and able to address their own poor integration. They would also be more likely prepared to consider or construct identities the social milieux seeks to neglect. Such identities as "citizen," "thoughtful consumer," "amateur scientist," "intellectual", or "philosopher"-which matter for public understanding of science - do not appear to be much encouraged by current social structural processes. In addition, large numbers of people are not high in need for cognition nor unaffected by motivated reasoning.

Consciousness, reasoning, and choice reside in individuals, and thus social structures are generated by individuals and must be continuously recreated by individuals. Nevertheless, these structures exert tremendous influence on each individual. Social structure is an emergent phenomena arising from individuals collaborating. Consider the social structures called 'organizations.' People seek to build organizations so they can pursue overarching goals, persist, and members of the organizations find it in their interests to insure such persistence. This becomes possible to the extent that organizations are arranged as adaptive systems with people as modular components. As organizations persist and come to coordinate the activities of large numbers of people, they can acquire processes, information, and other resources far beyond what individuals can. These form a source of power for the organization relative to individuals. Though a few people in the typical hierarchical organization might to an extent steer their organization, for most the organization is largely a fact of the environment - a thing that structures what they do and over which they have little effective input or even knowledge. As long as enough other people behave as though the organization were a reality, out of perceived legitimacy, complacency, fear, or ignorance, the organization remains a reality for all others.

A final aspect of the social manifestations of agency is social intelligence. A growing body of research suggests that social groups can collaborate together to solve problems in a way that manifests intelligence at a collective level rather than as a simple sum of individual efforts (Woolley, Chabris, Pentland, Hashmi, \& Malone, 2010). For example, research on transactional memory finds that groups develop divisions of labor with respect to who is responsible for remembering what (Hutchins, 1995). Thus, individuals can collaborate to produce higher order adaptive systems with emergent forms of intelligence that differ from a simple sum of individual intellectual efforts. Organizations naturally seek to efficiently combine the intelligence of their members and therefore seek to tap social intelligence.

\subsection{Agency and Cognition}

Agency involves cognition in multiple ways. Agents must cognize their contexts to choose appropriate identities. Identities involve goals of varying levels of abstraction. Cognition will be needed to appropriately apply such abstractions in given contexts. At a high level of abstraction, these goals constitute values. Values, when articulated and critically considered, require justification. Such justification will come in the form of belief systems (or "ideologies") regarding authority, personal worth, and what is valuable. Such belief systems 
will prove essential to reflexivity by suggesting how a coherent self can be built. At a more intermediate level, cultures provide conceptual structures for identities - that is, people need not understand or construct their identities from scratch but can tap ready-made identity constructs, such as the socially-constructed conception of "individual" identity Durkheim proposes. A complete theory of agency, then, also requires a theory of cognition.

Perhaps a useful starting point for building a theory of cognition is a coherentist analysis of knowledge and reasoning (Thagard, 2000; Thagard \& Kroon, 2006). In such a theory, beliefs can be viewed as nodes in a network. The links between beliefs are ones of consistency (coherence) and the totality of nodes and links constitute the belief system. When people consider a new belief (which can include empirical evidence and also "hot cognition"emotionally tinged information), they insert the new belief in their belief system and seek to identify the subset of their beliefs that maximizes total consistency. They then reject those beliefs not in this subset. A more realistic model would involve a limited consistency check against beliefs that come to mind rather than a complete search of all beliefs. Also, people highly interested in a subject may keep in memory alternate belief systems and occasionally consider their coherence relative to their primary belief system-allowing people to very occasionally jump to entirely different belief configurations.

The coherentist theory of cognition is consistent with Lakatos's (Lakatos \& Musgrave, 1970) philosophy of science. Lakatos points out that scientists do not simply reject a theory because there is clear disconfirming evidence. They will reject it only if they have an alternative theory that is overall more consistent with the data. Similarly, he points out that disconfirming empirical evidence can be rejected because the process that generated the evidence may have flaws. A theory may be too compelling, because of its internal consistency and consistency with other evidence, that it is more reasonable to question disconfirming evidence than to reject the theory. Coherentism, plus the hot cognitions created by social identities and other sources, might also explain the rejection of scientific facts by portions of the public. Hot cognitions (motivated reasoning) might be included in conceptual networks by stipulating sources of consistency that are not warranted by logic, inference, or other forms of reasoning.

What counts as coherent or consistent for an individual will depend on the form of reasoning the individual applies to a belief system. For example, people might reason in terms of emotional, metaphorical, or scientific consistency. In dual processing theory (Chaiken \& Trope, 1999), there is a distinction between central and peripheral processing in which central processing involves more thorough, time-consuming, and rational consideration while peripheral processing relies on heuristics that are fast but can make systematic and serious errors. Another basic reasoning distinction is between system and non-system reasoning (Mobus \& Kalton, 2015; Rosenberg, 2002). People who fully grasp how systems function can understand complex situations better than people who look for simple linear causal chains or, worse, associations. Emotional, metaphorical (or associative), group loyalty, peripheral, and non-system reasoning are likely more basic and biologically programmed, while logic, inference, system reasoning, and the combination of these in scientific reasoning depend on emergent cognitive development. People will vary in the degree to which they have developed rational thought and the extent to which they use it to overrule non-rational thought. The cognitive lapses involved in social identity theory, in which a person is systematically biased in favor of their own social group, likely depend on non-rational thought and are likely counteracted by cognitive development, to the extent that people achieve such development 
and to the extent they apply it to thinking about their social identities. Multiple forms of reasoning may exist in a person simultaneously. Also, this is not to assert the superiority of a scientific mode of reasoning for all purposes. Each form of reasoning has its value and proper range of application, but the non-rational forms must in general be tempered by rational thought to avoid destructive personal and social consequences.

A key point is that people need not have much drive toward consistency. People are adaptive systems, so if their current level of inconsistency allows them to achieve their goals, they have little reason to fix these inconsistencies. Even if the inconsistencies prevent goal achievement, people may not be aware of this or may not have the time or attention resources to address the problem. Their attention may be so preoccupied with other considerations due to social structural and other factors that they have no time to worry about inconsistencies. In addition, people may be rarely aware of inconsistencies in their belief system-as suggested above, they may conduct only a quite limited search of their most easily accessible memory contents when contemplating an issue. Such limited search may fail to discover inconsistencies. In addition, the "most easily accessible memory contents" are relative to the currently activated idea or belief, with the next considerations emerging from spreading activation that likely reaches only fairly related ideas. Thus, people may well learn different cognitive domains, such as tradition and science, in such a way that they are compartmentalized, and therefore they are unlikely to include more than one domain in any reasoning process. If so, they will not discover inconsistencies. Another form of compartmentalization may be a belief that different forms of reasoning apply in different domains, so rational considerations apply in science while emotional and intuitive considerations apply to tradition.

While there are many reasons that people may be content with inconsistencies, some may develop a drive toward greater cognitive consistency based on identities that stress knowledge and intellectual honesty. For such people cognitive consistency becomes a goal of their self-system. Also, some may have greater cognitive capacity to throw at both the exigencies of everyday life as well as inconsistencies in their belief systems. Empirically, however, it seems that most people are content to live with at least a moderate, if not high, level of inconsistency in their belief systems.

\section{AGENCY THEORY AND THE PUBLIC UNDERSTANDING OF SCIENCE}

While it is not yet sufficiently developed to offer a predictive theory of the public understanding of science, agency theory may provide a general framework for approaching the analysis of how the public understands science, the impact of social structural features on this understanding, and the possible effects of interventions such as public engagement. The objective here is to paint a broad picture of how agency theory could provide a rich approach for understanding public attitudes toward and knowledge of science and suggest potential research questions and hypotheses, not to provide firm evidence for particular views. The goal is theoretical breadth and suggestiveness, not empirical investigation. 


\subsection{The Status of Science and Public Distrust}

A general framework for public understanding of science will need some view of the status of science. This is best determined empirically, but even empirical data must start with a "prior" understanding, in a Bayesian approach to learning. This sketches the authors' priors.

Sociologists of science utilizing qualitative methods (Irwin \& Wynne, 2003) have questioned whether: science is a "uniquely privileged" perspective, science is an important force for human improvement, public ignorance is a major issue in the application of science to public issues, science is value-free and neutral as opposed to introducing values that challenge the legitimacy of applications of science to public issues.

The only source of knowledge about the world external to a person's subjectivity is empirical (ignoring Kantian-style a priori knowledge which is too general to provide specific information about most empirical issues). Science is the systematic and cumulative study of the empirical world. It has repeatedly shown its capacity to learn about and exert control over the empirical world through the development of a plethora of theories, processes, and technologies. No other approach to the empirical world has proved remotely as successfulwhether alchemy, astrology, or other assorted metaphorical belief systems. Consequently, science is a uniquely privileged perspective that deserves special recognition for its capacity to grasp and exert control over the empirical world. Whether that control has been an important force for human improvement depends on how it has been used-the application of science is determined by economic, policy, and political processes. Thus, the value of science for human improvement does not bear on the legitimacy or value of science, though the authors speculate that even those raising such questions would quickly retreat to the modern world from a stay in the Medieval one. On the other hand, current uses of science may, arguably, eventually lead to the end of modern civilization. This is not, however, primarily a fault of science.

While science is privileged, its instantiation has limitations. Science constitutes a social institution made up of people, with the potential shortcomings of all things human and social. A coherentist explanation of cognition allows that people build up well-developed coherent networks of beliefs that will be resistant to new theories and explanations, even without motivated reasoning and certainly with such reasoning. Thus, it is unsurprising that Kuhn (Kuhn, 1996) finds that scientists steeped in a theoretical tradition tend not to budge in the face of revolutionary new theories. On the other hand, scientists retire and young scientists without a lifetime of accretion of one belief network are better positioned to weigh alternative belief systems and select improved theories. While there is stickiness in science, in the long run science appears able to improve - revolutionary theories in the natural sciences are not just fads but appear to advance knowledge and the capacity to influence the physical world. Also, in the realm of most day-to-day as opposed to revolutionary changes, science does constantly adjust beliefs and theories in light of new evidence.

Science as a social institution is also corruptible. If, for example, commercial motives seep into scientific research, as they have in American medical research, and certain outcomes are lucrative and errors in findings not easily detected, questions arise about whether the research is scientific. Scientists facing various benefits or costs not aligned with the pursuit of scientific truth can be motivated to find certain results or hide other results, in violation of scientific objectivity. The solution for such problems is to build strong social structural barriers between the scientific enterprise and non-scientific motives and institutions. Treating science as just another self-interested or biased social institution does not address or correctly 
characterize the underlying problem. Another implication, however, is that public distrust in what portrays itself as science may at times be justified, which complicates analysis of resistance to science.

Gaps also exist between general scientific knowledge and how such knowledge applies in specific and complex contexts in which people are trying to make policy decisions. If these gaps are not filled using scientific methods, then scientific knowledge is no guide to firm facts about the context. And, of course, science is not able to adjudicate values, which invariably arise in policy decisions. Science itself does embody certain values, such as the values of knowledge, transparency, and research ethics or such values as simplicity or elegance, but these are general values that are beneficial for the scientific enterprise, not values that in some way challenge the legitimacy of applying scientific knowledge in policy contexts. Little, however, prevents self-interested actors or organizations from invoking scientific certainty in contexts in which existing scientific knowledge is insufficient or from implying scientific validation of value-imbued policy positions. Again, such maneuvers at times give the public good reason to be suspicious of claims to scientific validity in policy discussions. Selfinterested actors with resources can also, however, give the public bad reasons to be suspicious of issues around which there is scientific consensus, such as in the case of climate change.

\subsection{Public Misunderstanding and Distrust of Science}

Agency theory offers a number of ways of understanding public ignorance or distrust of science, including an explanation of traditionalism and its implications, the influence of social identities, and the role of cognitive processes.

\subsubsection{Traditionalism}

As already discussed, children are primed to rapidly and uncritically absorb social identities and roles. In addition, the internalized behavioral patterns generally imply certain ideas, including about social relationships, authority, personal worth, values, and reality that are further reinforced by cultural messages and conceptualizations. For example, in traditional societies understandings of the origins, purpose, and workings of the world are embodied in certain social roles, the arrangement of social roles, and the rituals prescribed for these roles. When people are later exposed to the ideas embodied in their subsumed identities and roles, these ideas seem, in the absence of much critical reflection, self-evident and "natural." Thus arises the compelling quality of tradition - with respect to social roles as well as the social organization, religious beliefs, and empirical beliefs embodied in these roles. Tradition can be compelling in other ways as well. Tradition offers people ready-made explanations for many perplexing problems of life, such as who they are, what they are meant to do, and how to make various consequential and difficult choices. Also, by placing a person within a known role in the social system, typically one that has a tradition-provided explanation of its worth and value, tradition can help make people feel valued. Traditions can be totalizing - offering a complete map of everything a person needs to know and do over their life and values and beliefs that make them feel good about this. Of course, some dominant cultural traditions can be oppressive for particular social groups. Such groups are often kept within their ascribed roles through rationalizations, structural disadvantage, and coercion-creating tensions that may 
lead to social change. Nonetheless, for many people tradition is compelling and can stimulate motivated reasoning on its behalf.

Traditionalism is the uncritical acceptance of tradition. Within modern societies, which tend to put people in situations that articulate or raise questions about the assumptions behind roles and identities, traditionalism also tends to have a cognitive dimension in which traditionalists become aware of the ideas and worldview behind the traditions they accept. For those steeped in a tradition and not overly inquisitive, this cognitive dimension serves primarily as a defense against challenges to tradition.

The question for public understanding of science is how traditionalism interacts with such understanding. Certainly traditional worldviews can conflict with science. In the U.S., substantial fractions of the public have traditional beliefs that conflict with scientific understandings of evolution and the origins of the universe. More broadly, the scientific method itself, which values raising questions, examining them empirically, and updating beliefs, would seem to be in conflict with any traditionalist approach to knowledge, in which certain truths are accepted as obvious and unchallengeable. While much of tradition concerns values, which science ultimately cannot legislate, it also contains or implies many empirical claims, including ones about origins, naturalness, and consequences that matter to the traditional worldview. Science may also weigh in on value claims by pointing to the consequences of values.

\subsubsection{Social Identity}

The attractions of tradition operate in substantial part through social identities, but the processes of social identity theory also have an impact independent of tradition. People like to think highly of their own social identities and poorly of other social groups. They adopt many cognitive biases to defend such thinking and, thereby, their social status and, implicitly, the coherence and cooperativeness of their own group. Such basic tendencies result in tensions, oppression, and, at times, genocide between social groups. Science or at least the appearance of science can be utilized as a weapon in such social politics.

In the $19^{\text {th }}$ century pseudo-science presented evidence of racial superiority and inferiority in the service of imperialism. Science itself was viewed by many as strong evidence of the superiority of Western civilization. Such uses of science or the name of science bred trust or distrust in science among social groups respectively benefiting or harmed. Currently, science figures as a point of contention in culture wars between the center and periphery. Urban elites embrace and assert the superiority of a culture in which rationality and science figure prominently, while many non-elites embrace and assert the superiority of a culture and related identities in which tradition, particularly religion, figures prominently. The latter distrust specific core scientific conclusions such as human evolution and the Big Bang. Those with stronger religious sentiments question the age of the earth and much of palaeontology. Another peripheral source of distrust of science lies in parts of the progressive left. This left is not necessarily poor or rural, but it embraces an egalitarianism that contrasts the powerlessness of the general public with the concentration of information, resources, and power in existing governmental and corporate institutions and thereby creates a picture of the peripherality of the public. This in turn drives distrust in applications of science, especially those benefiting corporations, such as GMOs, vaccines, and even alternative energy facilities on grounds of environmental impacts. 
A few elites at the dominant core of society are scientists and a good proportion of elites adopt identities that privilege rationality, systems thinking, and being informed by science and technology. On the other hand, the preponderance of the public does not perceive itself to be amateur scientists and many do not have identities that privilege rationality or science.

\subsubsection{Cognition and Distrust of Science}

Both traditionalism and social identity processes play out on the ground of cognition. Both depend most heavily on non-rational forms of reasoning that can be countered by cognitive development that enhances more rational forms of thought. The sheer prevalence of traditionalism and social identity politics even in ostensibly modern societies (Latour, 1993) suggests that non-rational forms of reasoning are dominant in many people.

A coherentist cognitive system can explain the tendency of people to cling to belief systems that make them feel good about themselves, make sense of their world, and are deeply elaborated despite scientifically disconfirming evidence against beliefs in these systems. As Lakatos suggests, people do not give up a belief system simply because of bits of disconfirming evidence. To give up their current belief system, they must have a better alternative belief system to adopt. People aware of only a few factual inconsistencies between their beliefs and science will not have much reason to switch and drop their current beliefs. Also, if people allow non-rational modes of reasoning a large role in deciding the coherence of beliefs, they will weigh emotional, metaphoric, peripheral and other considerations that do not privilege empirical facts in their belief system, but puts them on par with such considerations as positive feelings and sense making. Moreover, people not particularly aware of or concerned with inconsistencies can adopt an "all of the above" set of beliefs in which science and beliefs inconsistent with some aspects of science are both accepted.

This and other background considerations suggest some hypotheses about the possible distribution of belief systems in the public. The public may consist of five basic types of people. Some may be "the content"-content with an "all of the above" approach because they are under little adaptive pressure to immerse themselves in both science and tradition and reconcile any inconsistencies they may find between them. As previously discussed, people need not have much drive toward belief consistency. A second group may be "weak defenders of tradition" - namely, they may perceive a conflict between science and tradition on a few key empirical issues. They resolve this conflict by simply agreeing with tradition over science on a highly focused set of issues that are critical for tradition and otherwise accepting science in the empirical realm and tradition in the realms of values, norms, the after-life, and so forth. The preponderance of the public may well be the content or weak defenders of tradition. Such positions are adaptive for many people - they are able to happily accept both science and tradition for all practical purposes and use what they wish from both. A third group may be "weak defenders of science"-people who resolve perceived conflicts between science and tradition by siding with science on highly focused empirical issues in contention but otherwise accepting science for empirical matters and tradition for non-empirical ones. Besides some portions of the Roman Catholic church hierarchy, few people come to mind in this category. The remaining two categories have to do with strong defenders of science or of tradition, and these categories are apt to be populated but not heavily. A strong defender of science rejects tradition and vice versa. Strong defenders must reject one or the other of two important 
touchstones of American culture. They may have a strong understanding of both belief systems and concluded that one is incorrect. Or, perhaps more prevalently, they may have strong exposure to only one of the belief systems in their structure of communication, with the result that they find the system they understand best as most coherent and, therefore, believable.

The above typology makes sense of patterns of data about belief in evolution. The general social survey (GSS) has found that only 52\% of Americans correctly answer a science knowledge question asking about whether humans developed from earlier species of animals (National Science Board (NSB), 2014). When, however, the question is presented with an alternative wording that starts with a clause asking whether scientists believe in such evolution, $75 \%$ of Americans correctly answer the question. This finding could be explained by weak defenders of tradition, who reject the science of evolution but are aware of what scientists believe.

A more sophisticated but as yet unpublished analyses based on a nationally representative Internet panel data (Aaron Maitland, Roger Tourangeau, Ting Yan, Robert Bell, \& Peter Muhlberger, 2016) finds similar changes in the number of correct responses between the original human evolution question and the same question, but with the word "elephant" substituted for "human." This suggests that most of those who do not believe in human evolution reject only human evolution and not the evolution of other species, consistent with the hypothesis that weak defenders of tradition will only focus narrowly on the most prominent issues of contention between religion and science. The data also shows only modest differences in knowledge of evolution and general knowledge of science between those who reject evolution and those who do not. This is consistent with the view that most of those who reject evolution do so while nevertheless well aware of science and happy to apply it. The largest differences are between those who accept only an entirely secular view and those who embrace young earth creationism. The former score well above average on general science knowledge questions while the latter score appreciably below average. This is consistent with the hypothesis that some fraction of these people form distinctive communities in which they are exposed primarily to either faith-based or scientific views and information.

A final issue concerns the role of scientific reasoning in the tension between science and tradition. People who are steeped in rigorous scientific thought, should, it may seem, favor science over tradition or at least find a compromise between the two in which science wins most if not all empirical arguments. Indeed, scientists are more likely than the general public to, for example, reject religion (Masci, 2009), but not all scientists do and some seem quite capable of performing well as scientists while holding strong religious views. These facts might be explained through these scientists developing a defensible compromise between religion and science or through motivated reasoning and compartmentalization, as previously discussed.

\subsection{Social Structure and Public Misunderstanding and Distrust}

Individual-level processes cannot be fully understood without placing them in the social system that shapes and directs these processes. Social identity, the structure of communication and its impact on attention, and the embeddedness of people in organizations and other structures all suggest that little goes on at the individual level that is not appreciably also a part of the larger society. Human psychology is permeated by the social, so to study a complex phenomenon such as public understanding of science by focusing primarily at the individual 
level is inadequate. A minimal step in the right direction is to understand the chief social structural features that may bear on public understanding of science. This might be done relatively uncontroversially by exploring the distribution and content of social identities that bear on such understanding, the structures of communication (media, other organizational communications, interpersonal discussion) in which people find themselves and how these shape understanding, and the organizational and other larger social structures in which people participate. Even this, however, is insufficient because social structures and individuals are part of a social system with crucial implications for understanding of science. Characterizing this system is apt to be a rather controversial and exceedingly complex undertaking. The social structural parts, however, can best be understood in terms of how they function in a systemic whole that to a degree maintains a status quo. Thus, this section will dive into the most controversial issue - the overall systemic context within which understanding of science arises. It will propose a controversial and speculative description of that systemic context, but the description will be one with rich ramifications for public understanding of science. Whether or not the description is substantially accurate or not is less relevant than whether thinking in systemic terms could yield insights without which the study of the public understanding of science would fall far short of explaining its phenomena.

\subsubsection{A Modest Description of the Controlling Heights of the Social System}

For what purposes is science pursued and to what ends? What is the role of the public and of various elites? What are the system's goals and how does it pursue them? To answer these questions, it is necessary to start with a very general description of the social system.

In the U.S., science functions as part of a broader system of substantially oligopolistic capitalism in which a small elite of business leaders have for many decades and with some success sought to monopolize resources and either actively undermined or enjoyed the spontaneous decline of the bases of opposition to their power, including academia, labor unions, left and liberal political opposition, social movements, social organizations, and government itself (Gilens \& Page, 2014; Mayer, 2016; Newfield, 2011; Pierson \& Hacker, 2010; Piketty, 2014; Readings, 1997; Skocpol, 2003). Such aggressive consolidation of power has been made possible because a majority of this elite favors such consolidation. The elite is not of one mind and a minority realize that the country would function far better as a balanced system with alternative bases of power. In particular, these alternative bases of power existed because they served critical social structural functions that cannot be reduced to business values, such as socializing new generations in something other than corrosive self-interest. Though the elite is divided we will, for simplicity, refer simply to "the elite" as that part of the business elite that has proven dominant.

In its pursuit of hegemony, the elite had to overcome a significant hurdle to elite control - namely, the pursuit of control by a vanishing percent of the population in a country in which political power is elected by a majority of voters. The elite solved this problem primarily through wedge politics and a vast messaging apparatus. Wedge politics pit various social identities against each other-periphery versus core, sensible average people versus useless eggheads, religious versus secular, whites versus minorities, non-poor versus poor, and so forth. Of course, a rich, powerful elite delivering a message about good, peripheral, ordinary, religious, hard-working people is not typically by itself compelling, so the elite needed to enlist substantial networks of messengers whom their public would trust. They have, in fact, built a 
vast messaging apparatus including religious figures, academics, public intellectuals, think tanks, lobbyists, politicians, judges, interest groups, newspapers, radio talk shows, and a popular television network.

\subsubsection{Implications for Science}

On the whole, the elite does not benefit from a public that is engaged with policy or thinks critically. It benefits from a public that focuses on work, consumption, and family life, follows rather than believes it can make up its own mind, and is engaged with social identity wedge issues. In the realm of public life, a country that wanted engaged citizens - engaged with science or other policy issues-would serve up citizenship identities and values to students from early life on, would thoroughly educate students on the most pressing policy debates of the time, would give citizens time and public spaces in which to learn about and engage each other about political and policy issues, and much more (Ackerman \& Fishkin, 2005; Barber, 1984). This does not remotely describe the U.S. today. Existing organizations, whether federal agencies or public interest groups, systematically avoid thoughtful public engagement (Muhlberger, Stromer-Galley, \& Webb, 2011)

Similarly, a country that wanted critical, scientifically-minded thinkers would encourage citizen science on a vast scale and would intensively educate students in exercising critical and scientific thinking in public and consumer affairs. In particular, the latter would be best served by educating students on the insights of the social sciences and humanities with respect to political, public, social, and consumer issues - building a broad perspective from which the public could reason about values and facts in social and political life. Such a country would develop social identities and ideologies of value and self-worth that would invite broad swaths of the public to critical and science-pertinent engagement. There has been growth in "geek" or "genius" identities, but these are circumscribed because they are meant to be exceptional.

The picture with respect to scientific and critical thinking is more mixed than it is with citizen engagement with policy issues, no doubt in part because elites do need to educate technocrats who can innovate and maintain existing productive infrastructure. Not surprisingly, universities are increasingly focused on job training, including in the sciences, rather than in shaping critical and scientifically-minded citizens and consumers (Newfield, 2011; Readings, 1997). At more elite institutions, science education entertains the critical thinking needed for innovation, but this is a modest percentage of even the science and engineering workforce. The social sciences and humanities, which are important to connecting critical and systematic thinking to the realm of public affairs, are either shrinking at universities or under budgetary and political attack. A certain fraction of Congress would be happy to eliminate research budgets for the humanities, social sciences, and those parts of the geosciences that pertain to climate change.

Overall, the existing social structural conditions in the U.S. discourage engaged, critical, and scientifically-minded citizens and consumers. These conditions insure that most of the public does not have the education, opportunity, time, leisure time, resources, or encouragement to pursue critical reasoning or engage the science applicable to policy and consumer issues. A possible research approach to understanding this would be to examine or experiment with public engagement on science issues across multiple demographics and then project, using time-use data and information about education, resources (Brady, Verba, \& 
Schlozman, 1995), identities, the structure of communication, economies of attention, individual differences, ideologies of worth and value and so forth, how many and which people could realistically pursue such engagement. There are no doubt substantial socioeconomic inequalities in who could participate. In addition, comparison of people who are engaged with policy against those who are not might identify both individual and structural differences contributing to engagement.

\subsection{Intermediate Social Structure}

Besides pressure from the commanding heights of the social system, numerous more intermediate social structures affect public understanding of and attitudes toward science. Many of the most relevant such structures fall under the notion of structure of communication - standing patterns of communication between people.

The mass media and social media are likely to be important means by which attitudes toward science and perhaps understanding of science are shaped. The mass media devote only a small fraction of their news coverage to science (Tyndall Report, 2015), and only a portion of the public regularly follows the news. Social media may have deeper penetration of the public, but more needs to be known about what science news and information is conveyed by such media, how this is structured, and what impacts it has on participants. Many people go to the Internet more generally to learn about science issues either by asking specific science questions or looking at science-related articles on online newspapers (National Science Board, 2016, p. 7).

A critical question is the degree to which public opinion and perhaps knowledge of science is influenced by opinion leaders with the public itself. Systems theory suggests that people may organize the processing and retention of information through transactive processing and memory (Hutchins, 1995) in which people in close contact create a division of labor with respect to processing and memory, particularly if some people are more interested in and capable with respect to a topic. If so, then opinion leadership could prove quite important for science policy and attitudes. Even opinion leaders may take their cues from yet more capable leaders, creating a hierarchy of leadership in the public that may trace back to belief communities and organizational connections. Certainly organizational leaders seeking to influence the public have developed networks of people to spread information or disinformation.

The evidence for the existence of opinion leaders with respect to policy issues is mixed, with some studies finding opinion leaders with important effects and others with more ambiguous findings (Bennett \& Manheim, 2006; Burt, 1999; Robinson, 1976; Troldahl, 1966). In general, the issue is much understudied, perhaps in part because of the likely cost and size of the task. Ideally, research on opinion leadership would start with a substantial random sample of the public and then use snowball sampling to identify the network of people and the structure of that network who lead opinion in the mass public. Once the network is identified, it would be desirable to see it in action when some pressing new policy or attitudinally-relevant issue comes to prominence in the media. The affordability of such research might be enhanced by studying not just science attitudes but attitudes relevant to other political and social issues, making the research multidisciplinary. A model for such research could be the large project on contextual effects in politics conducted by Huckfeldt (1995). Interesting questions include 
whether the leadership network would be the same for different types of issues and how rapidly the network changes over time.

If a representative sample of the public and its opinion leaders is available, this would also be an opportunity to study how media affects science attitudes and knowledge. Researchers could insert themselves into participants' social networks by asking to, for example, "friend" participants on platforms such as Facebook. Ideally, researchers would insert themselves into and record as many social media platforms as a person uses. Software on participants' computing devices could directly record social media and Internet use. Rich media data could be obtained over time either directly through "spyware" or indirectly through recording social media use as "friends" of participants. In addition to recording, researchers could experimentally introduce science issues and information into social media and observe how the information travels and is transformed online and, resources permitting, in people's offline interactions. Near field detection on cell phones would be helpful in discovering who is talking with whom, as might software that records cell phone interactions. Finally, researchers could observe as major science issues are reported in the media, recording the media to which participants are exposed and observing how this information is transformed in people's minds and interactions. Perhaps such research could take place in a locale in which the researchers know that important new science information will become available. They might, for example, work with natural scientists who are nearing release of a substantial discovery or policyrelevant statement.

In addition to directly tracking the structure of communication, another avenue for research would include charting the public's identities favorable or unfavorable to science. Losch and Nzekwe (2015) have found that science identities play a valuable role in undergraduate science education. Much more could be done to identify science-relevant identities in the general public and determining their content. How these identities are distributed by education, SES, life experiences, and exposure to science information should be revealing as to the sources of science attitudes and understanding. As previously explained, identity is usually only partially conscious in the form of linguistic structures that are accessible to the person and that might or might not correctly capture a person's automated processes. Internalized linguistic structures likely do capture these automated processes. Thus, fully capturing identity may require more indirect methods, such as asking about tell-tale signs of internalization (Koestner, Losier, Vallerand, \& Carducci, 1996; Ryan \& Connell, 1989) or using reaction times to determine which identities are automated or internalized.

Research in public understanding of science might also benefit from automated or semi-automated analysis of big data from social media and search websites. This could clarify what news and attitudes are reaching the public from what sources and the structure of communication between organizations and the public and within the public. As big data analytics come to allow better extraction of useful information from text, analyses may also begin to capture the meaning of communications. Already, topic modeling could prove helpful in identifying the general content of different messages. Eventually, machine learning and natural language processing may be up to the task of automatically or semi-automatically extracting the mental map or conceptual network in text, providing a wider window into meaning.

In addition, researchers should more closely examine the messaging networks utilized by elites to influence the public. Starting with a number of prominent science issues, research could examine how media stories about these issues originated, the content of these stories, and 
which organizations and actors took up the stories and how they were transformed when repeated. Researchers may seek to identify the mental map in each story and use network analysis (or even just a comparison of terminology) to determine the closeness of stories from different sources. In addition to references within the stories and their timeliness, this could clarify the existence of standing patterns of message transmission that constitute messaging apparatuses or structures. This could also clarify how these apparatuses function, including how they distort or simplify their subject matter.

\section{PUBLIC ENGAGEMENT ON SCIENCE AND SCIENCE POLICY}

Achieving meaningful public engagement with science and science policy is both a moral imperative and a potentially difficult and risky undertaking.

Human agency is a moral good. Giving people the power to choose their own path in life based on critical reflection is a core value of modern civilization and the basis of what people think of as freedom and self determination. Thus, that which contributes to human agency is a moral good, while that which seeks to circumvent this agency is morally undesirable. Though circumventing people's agency on occasion may not strongly undermine that agency overall, a cautionary principle is needed to the effect that people's agency is to be respected even in small matters because it is not known how readily small matters accumulate to strongly undermine agency. People often become what is demanded of them and leaving a multitude of choices outside their agency could whither that agency.

With this in mind, leaving the public out of decisions on science policy is appreciably more than a minor infringement on their agency. Nanotechnology, genetic modification, artificial life, climate change, energy, ecosystem change, mass extinction, and numerous other science and technology issues pose pressing ethical questions that, in a democracy, can only be legitimately decided by the public (Benhabib, 1994). Given the likely pervasive effects that decisions regarding such science and technology will have on the future of all Americans, involving the public in decisions is essential for their agency. Nor is it sufficient to conduct standard polls to obtain public opinion on such issues because responses can only reflect the public's values and choices if the public is informed - that is, it knows what it is talking about. The only democratically legitimate and ethical option for obtaining guidance on such pressing issues is to engage the public in learning about such issues and then in thoughtful discussion of the issues.

Means of meaningfully engaging the public in such decision making abound. One wellknown approach is deliberative polling (Luskin, Fishkin, \& Jowell, 2002), in which a representative sample of the public is selected and then, either face-to-face or online, are presented with background information and given a chance to deliberate among themselves and query experts. Research shows that such engagement increases knowledge of the issue discussed and often substantially shifts attitudes (Barabas, 2004; Farrar et al., 2010; Luskin et al., 2002). Countless other practically tested methods exist for informed public deliberation and engagement, as outlined in Participedia (www.participedia.net), each with different strengths and purposes. Numerous organizations such as AmericaSpeaks, Study Circles, and Public Agenda have experience engaging the public with such methods. Online approaches to deliberation, such as those utilized by e-democracy.org, have the potential for substantial reach. An umbrella organization, the National Coalition for Dialogue and Deliberation points to numerous organizational and other resources available for deliberative engagement. As for 
public engagement with amateur science, which can help familiarize citizens with scientific methods and reasoning processes needed to understand policy issues, citizenscience.org estimates over one million participants.

Public engagement with science policy is morally imperative, methods for informed public engagement are available, and an organizational capacity to execute such engagement exists and could be expanded. Nevertheless, the amount of informed engagement or citizen science in the U.S. reaches a seemingly negligible portion of the public. For example, the over one million citizen scientists citizenscience.org claims would constitute less than $1 \%$ of the age 18 to 64 U.S. population, and this does not broach the issue of how many of these projects actually involve participants in ways that build their understanding.

If elites wanted widespread engagement, vastly more resources would be expended than are currently and, likely, far more people would be engaged. Instead, some evidence suggests that public interest groups and government agency personnel shun deliberative public engagement in favor of methods better suited to pushing the public to a predetermined conclusion (Muhlberger et al., 2011). The preponderance of the public is uninformed and leaders prefer to treat it as a resource that can be persuaded to embrace certain viewpoints rather than as agents that should be given the balanced information needed to make up their own minds. As previously explained, a small fraction of the population exerts outsized influence on the social, economic, and political systems and this fraction benefits, at least in the medium term, from an under-informed and easily manipulable public. Social structural conditions, which are at least influenced if not controlled by these elites, help insure just this kind of public.

Business elites typically want particular outcomes when it comes to science and technology policy issues, because they have generally favored free reign to pursue innovations and industry, regardless of potential ethical implications or global consequences. Elite preferences will likely be to give free reign to nanotechnology, genetic modification, and artificial life while ignoring ecosystem change and mass extinction of the Earth's species. In the science policy domain of climate change, a powerful messaging system is opposed to knowledge and action. Clearly, some elites are concerned with climate change and the impending Apocalypse, but these elites have not as yet had a decisive influence on public opinion in favor of effectively addressing the issue. Current actions on climate change will not be effective in avoiding catastrophic changes to the climate system.

Successful public engagements on specific science policy issues typically need to be blessed and funded by elites. All else will be either irrelevant or pursuing asymmetric action against concentrated power and resources. Academics and dialogue organizations pursue deliberative engagement with thousands of citizens a year at a price of millions of dollars. In contrast, elites expend tens of billions a year in advertising, public relations, political campaigns, messaging machines, think tanks, academic chairs, media organizations, lobbyists, and pressure groups. These expenditures lead to public influence efforts that almost never provide balanced information and purely rational appeals. They play to and help insure the perpetuation of a public governed by non-rational cognitive processes. Simultaneously, elites benefit from ineffectual deliberation efforts by pointing to hundreds of such efforts as evidence of a commitment to democratic engagement. Also, some of the best intellects with respect to social issues and public engagement are tied up pursuing these efforts, removing them as potential leaders of more serious challenges to concentrated power. 
Beyond the societal imbalance between opportunities for reasoned engagement versus manufactured consensuses, successful public engagement with a politically significant fraction of the public runs a risk of unleashing dangerous forces. Currently, a substantial portion of the public falls into the categories of 'the content' and 'weak defenders of tradition.' Neither of these types have fully wrestled with potential inconsistencies between tradition and science, and we do not know what would happen if they did. A strong rejection of science is not unlikely. People do come out of deliberations feeling good about their fellow deliberants, even those with whom they disagree, and with changed and better informed opinions. Most deliberations, however, focus on policy issues about which participants know little and whose connection with their values are at best obscure. Participants readily coalesce around the more sound expert opinion presented in background briefings. Researchers, however, have little experience with deliberations that point out strong conflicts between science and tradition. Even if participants in such deliberations emerged with a warm glow, if they become a politically significant factor on some policy issue there is apt to be backlash from any messaging machine that prefers different conclusions. Then there would ensue a contest between the public's capacity for reason and its likely more substantial capacity for nonrational thought, with vastly more resources poured into reinforcing the latter.

Lest we be dubbed the Eeyores of public engagement, some possibilities exist for strengthening deliberative public engagement and for pursuing forms of engagement that have at least a faint hope of breaking through concentrated power. Researchers should be contemplating strategies to grow the scale of effects of deliberative engagement. After a representative-sample deliberative poll, organizers might seek to amplify the impact of the results on the public. This might be achieved, for example, through a publicity campaign, including having deliberants select representatives who can speak about the deliberation reasoning and results with the mass media and disseminate results in social media. Another possibility would be a website in which the public can learn in depth about the deliberation. Such a website might seek to match the values and demographics of site visitors with specific deliberants and give the visitors a chance to see the similarity of these deliberants and their thoughtful views about the issues. Social identity processes including trust in similar others should prove more persuasive than just seeing an averaged poll result. Deliberations might specifically seek to include opinion leaders and perhaps celebrities to enhance their impact on the larger public.

Another type of strategy would be to adopt deliberative public engagement methods that could reach larger publics. Online engagement offers one possibility. Teledemocracy (Becker \& Slaton, 2000) could reach a large public at low marginal cost. In teledemocracy, people are sent background materials by mail, asked to discuss the materials with family and friends, and are told they will be contacted by an interviewer who will ask about their final views. Some evidence suggests that the background material, not discussion, is what enhances the knowledge of deliberants (Muhlberger \& Weber, 2006), though having to explain one's conclusions to an unknown person may motivate careful reading of the materials. More generally, engagement researchers need to learn more about what happens, particularly in the long run and in the face of non-rational persuasion attempts, when people are confronted with tensions between science and their values and traditional beliefs.

Beyond seeking to shore up deliberative public engagement, organizers may wish to consider alternative forms of engagement that are more likely to be self-sustaining and selfreplicating - hence able to create a mass movement capable of resisting concentrated power. A 
possibility is the development of democratic community. Much of the public feels it should be "citizens" and engaged with the community, but they have little idea of how to go about this. Organizers may succeed in developing small citizens' groups that focus on getting to know each other personally, talking about concrete community problems, and taking small actions to address these problems. Small successes would enhance motivation and group cohesion and allow the groups to address larger and more complex problems. A successful group would have its members bring in more potential members and eventually spawn new but strongly interconnected groups. Interconnections could be nicely managed in the form of sociocracy (Endenburg, 1998; Pivato, 2009). As these groups become more prevalent, they can address and discuss ever wider social issues. With time, these groups could deliberate and publicize their views on major science policy issues. Even if such groups could succeed in just a few larger cities or a few percent of the public, their views could have an impact on science policy issues in that these views would be the considered, informed, vocal, and unmanipulated views of the public.

\section{CONCLUSION}

This paper has introduced a theory of human agency that synthesizes insights about agency from a number of established psychological theories, some of which shade into sociology. Agency theory addresses two key difficulties in research on public understanding of science. One is the need for a theoretical framework that can encompass both psychological and sociological explanations. The second is the need for a framework that can encompass both the evident non-rational nature of public opinion on many policy issues but allow for people to develop the more rational thinking needed for real public understanding of science.

Agency theory clarifies the strong hold that tradition has on many people and the tensions between such traditionalism and science. In particular, children rapidly absorb the behavioral patterns and understandings of culturally prominent identities while incapable of critically evaluating what they absorb or, eventually, remembering the details and context of what they have absorbed. Such lack of awareness is consistent with encapsulation and subsumption - aspects of agency theory that can explain why people may be appreciably unaware of the contents of identity "modules" they have absorbed. When later encountering the cultural beliefs inscribed in their absorbed identities, these beliefs will appear to be selfevident. Unquestioned cultural beliefs are in some tension with science in that a scientific mindset involves questioning and rigorous testing of apparent truths, and at times science directly conflicts with cultural beliefs pertaining to the empirical world.

Uncritically absorbed identities and unquestioned truths work well in traditional societies, but modern societies typically require people to negotiate their lives through a multiplicity of roles and identities, both in themselves and in others, with accompanying questions raised about apparent truths. In modern societies, people are pressed to resolve conflicting internal identities. They can do so through reflexivity and self-development. In reflexivity, a person builds a model of an identity by describing that identity and its outputs to themselves - thus, the model is linguistic. They can use language and accompanying reasoning processes to think through the identity, clarifying conflicts with other identities and other inconsistencies and problems. Values, a sense of ethics, valuating belief systems, selfknowledge, and knowledge of society and history can help the reflexive process develop a more unified self. Self-development requires the additional step of conscious attention being 
used to reshape identities to be consistent with reflexive choices. Attention is used to retrain habitual actions to conform to reflexively modified or chosen identities. Agency is the capacity for reflexivity and self-development. It can be thought of as free choice and self-determination.

Agency theory also requires a theory of cognition in that agents must cognize their contexts to choose appropriate identities, identities imply and motivate certain cognitions, identities come in packages that can include conceptual content, and reflexivity operates through cognition, including valuative belief systems or ideologies of authority, personal worth, and value. A coherentist conceptual network model of cognition may prove fruitful. In such a model, beliefs form nodes that are connected with edges of varying degrees of consistency. In a coherentist account, people do not dispense with a belief system simply because of one failure, nor should they. They will dispense with a belief system only when a better alternative system, that explains more than the current system, is in view. This makes belief systems "sticky" and difficult to change. In addition, as adaptive agents, people only need as much consistency as necessary to achieve their goals, which may be far from perfect consistency. People may be unaware of or not have the time to address inconsistencies. Beliefs may also be compartmentalized so that a limited search of beliefs most strongly associated in memory does not bring to light inconsistencies between belief networks.

What counts as consistency or consistency-conferring reasoning may vary across persons and contexts and can include non-rational and rational types: emotional, metaphoric, associative, peripheral, non-systemic, logical, inferential, and systemic. Cognitive development involves developing a capacity for rational thought, though other forms of thought may play a role even in people fully capable of rationality.

Persons are modules within larger social structural systems that shape and direct their agency. Individuals are connected to social structures through their social identities and social identity processes. The latter make people highly biased in favor of their own groups while biased against other groups. More sophisticated cognitive development can undermine such biases, though without eliminating social identity itself. Social structures can alter the focus of people's attention and their patterns of communication - the economy of attention and the structure of communication. Thereby, social structures can affect people's goals and their identity integration. Structures can also influence the available distribution of identities, the ease with which various goals can be achieved, valuative belief systems, and environmental identity triggers. People high in need for cognition and low in motivated reasoning may be less susceptible to social structural shaping. Collective intelligence suggests the possibility of memory and reasoning distributed across groups of people.

Agency theory helps explain the role of tradition in modern societies and its convoluted relationship with science. Tradition has proved remarkably resilient in ostensibly modern societies. This can be explained by the seeming obviousness of traditions inscribed in social identities. And, despite pressures toward reflexivity, tradition can be resilient due to the possibilities for tradition to survive through multiple avenues, including the capacity for people to live with contradictions. Contradictions in identities and beliefs are typically ignored if people are achieving their goals or if they are unaware of a sufficiently compelling alternative belief system. People can be too distracted to notice contradictions or too busy to invest the time to address them. Compartmentalization of belief networks can insure a low incidence of thinking about contradictions between science and tradition. Some people may utilize forms of reasoning, such as association, that fail to detect real contradictions. Some may develop views that resolve or appear to resolve tensions between tradition and science. Tradition may 
stimulate motivated reasoning in its defense by offering people ready-made explanations for key problems of life, such as who they are, what they are meant to do, and how to make difficult choices. This operates in substantial part through identity. Other forces may push for greater consistency, both individual differences and social structural factors. At a socialstructural level, belief communities emerge to defend traditional identities and associated beliefs. In the U.S., an important social structural difference is between a core of urbanites who emphasize science and a periphery of more rural people who emphasize religion.

Considerations such as those above suggest a potential typology of beliefs in the public with respect to tradition and science. This includes: a) the content who happily include both tradition and science in their beliefs because they are unaware of or do not care to examine tensions between these beliefs, b) weak defenders of tradition who side with tradition in a few key factual matters but otherwise accept both belief systems, c) weak defenders of science, d) strong defenders of tradition who reject substantial swaths of science and e) strong defenders of science. This typology helps explain research findings on public attitudes toward evolution.

The larger social-structural context of science can in part be understood by clarifying the general purposes of the social system. Multiple lines of evidence suggest that the purposes of the social system are increasingly under the influence of a portion of the business elite. Not surprisingly, the social system is arranged in a manner that concentrates power at the top rather than involving a wide public. Social structural features and influences could be arranged to strongly involve people in public policy issues, including science policy. Instead, conditions including the form of education, opportunity, time, leisure time, and resources discourage engaged, critical, scientifically-minded citizens and consumers. The public is encouraged to focus on consumption, family, and narrow social identities that can be used as wedge issues. Elites do need scientists and engineers who can think creatively and question existing assumptions. Education, however, has been substantially refocused on job training at most universities rather than broad thinking about social and political matters. A few more elite institutions teach innovative thinking.

Researchers might study the conditions that give rise to a disengaged public by examining time-use patterns of everyday life, education, engagement resources, available and utilized identities, the structure of communication, economies of attention, individual differences, ideologies of worth and value, particularly across people who are deeply engaged and those who are not. This will no doubt show substantial socioeconomic differences and identify multiple roadblocks to engagement by ordinary people. Research is needed to develop better means of measuring identities and their effects. More research is also needed on how the public organizes its opinions on key policy issues, particularly the possibility of an important role of opinion leaders and the structure of message and cue taking between opinion leaders and between opinion leaders and organizations, including organized belief communities and various media. An interdisciplinary effort that included the spread of views regarding science policy along with other policy issues may make such research more attractive to funders. Researchers might introduce software on participants' devices to track the flow and content of communications. Policy issues could be experimentally introduced into a network of participants. Big data analytics, particularly of text and network connections, could be helpful in following the flow and transformation of beliefs. Researchers could also train their efforts on identifying the structure and functions of the messaging machines used by elites.

Public engagement on science policy is morally imperative, but also a difficult and risky undertaking. Democratic legitimacy requires authoritative public input on the ethics of 
key science policy issues that will likely greatly affect the public in the future, including such issues as climate change and genetic modification. Authoritative input depends on an informed public. Given that the public is largely uninformed with respect to such issues, authoritative input requires approaches such as deliberative polling. Such approaches have been well researched and various organizations offer a capacity for well-done deliberation efforts. Nevertheless, a majority of business elites have already taken positions on many science policy issues. They have been in favor of unbridled research and commercial application and have not been great defenders of the environment in recent decades. Some evidence indicates that elites reject deliberative public engagement in favor of means in which they better control the outcome. Deliberative public engagement reaches only a small fraction of the public, while the messaging machines of elites reach much of the public and are lubricated with vastly more funding. Currently, deliberative public engagement poses no threat to elite control. Were it to become so, a quite asymmetric power struggle would likely ensue. In addition, deliberative engagement that pits science and tradition may unleash the potential for the "content" and weak defenders of tradition, groups that likely make up the majority of the public, to more strongly embrace tradition over science.

There may be better ways to pursue public engagement. This paper discusses means of strengthening the effects of deliberative public engagement on the wider public. Deliberation efforts might focus on opinion leaders. Deliberation results could be disseminated online in a way that people could see the reasoning of participants similar to themselves. Online deliberations could reach large numbers of people, if only the public could be steered to participate. Teledemocracy, which combines reading materials with eventual phone interviews, could reach larger numbers of people and educate them on a subject. Finally, organizers may wish to experiment with "democratic community," an approach that goes beyond existing deliberative engagement by being self-sustaining and self-replicating, potentially creating a larger engaged public. Such groups should prove attractive to the many people who would like to be "citizens" but do not know what that identity entails. A group would begin as people getting to know each other, taking on small civic activities and mutual aid, and eventually introducing larger and more complex issues. Each group could spawn new groups and the collection of groups would be increasingly effective in having its voice heard. Intergroup coordination could take place along the lines of the sociocracy model. If only a few percent of the public in a few cities could be thus organized, it would still represent a substantial new force on policy issues.

\section{REFERENCES}

Aaron Maitland, Roger Tourangeau, Ting Yan, Robert Bell, \& Peter Muhlberger. (2016). The Effect of Question Wording on Measurement of Knowledge About Evolution. Public Opinion Quarterly (Under Review).

Abelson, R. P. (1995). The Secret Existence of Expressive Behavior. Critical Review, 9(1-2), 25-36.

Ackerman, P. B., \& Fishkin, P. J. S. (2005). Deliberation Day. Yale University Press.

Bandura, A. (1976). Social Learning Theory (1st edition). Prentice-Hall.

Bandura, A. (2001). Social Cognitive Theory: An Agentic Perspective. Annual Review of Psychology, 52, 1-26.

Barabas, J. (2004). How Deliberation Affects Policy Opinions. American Political Science Review, 98(4), 687701.

Barber, B. R. (1984). Strong Democracy: Participatory Politics for a New Age. Berkeley: University of California Press. 


\section{PETER MUHLBERGER \& LISA PYTLIK-ZILLIG}

Becker, T. L., \& Slaton, C. D. (2000). The Future of Teledemocracy. Westport, Conn.: Praeger.

Bem, D. J. (1967). Self-Perception: An Alternative Interpretation Of Cognitive Dissonance Phenomena. Psychological Review, 74(3), 183-200.

Benhabib, S. (1994). Deliberative Rationality and Models of Democratic Legitimacy. Constellations, 1(1), $26-52$. http://doi.org/10.1111/j.1467-8675.1994.tb00003.x

Bennett, W. L., \& Manheim, J. B. (2006). The One-Step Flow of Communication. Annals of the American Academy of Political and Social Science, 608, 213-232.

Bowles, S., \& Gintis, H. (1986). Democracy and Capitalism: Property, Community, and the Contradictions of Modern Social Thought. New York: Basic Books.

Brady, H. E., Verba, S., \& Schlozman, K. L. (1995). Beyond SES: A Resource Model of Political Participation. American Political Science Review, 89(2), 271-294.

Burke, P. J. (2006). Identity Change. Social Psychology Quarterly, 69(1), 81-96.

Burt, R. S. (1999). The Social Capital of Opinion Leaders. Annals of the American Academy of Political and Social Science, 566, 37-54.

Cacioppo, J. T., Petty, R. E., Feinstein, J. A., \& Jarvis, W. B. G. (1996). Dispositional Differences in Cognitive Motivation: The Life and Times of Individuals Varying in Need for Cognition. Psychological Bulletin, 119(2), $197-253$.

Carver, C. S., \& Scheier, M. F. (1981). Attention and Self-Regulation: A Control-Theory Approach to Human Behavior. New York, Heidelberg, Berlin: Springer-Verlag.

Carver, C. S., \& Scheier, M. F. (1999). Themes and Issues in the Self-Regulation of Behavior. In J. Robert S. Wyer (Ed.), Perspectives on Behavioral Self-Regulation (Vol. XII, pp. 1-106). Mahwah, New Jersey: Lawrence Erlbaum Associates.

Chaiken, S., \& Trope, Y. (1999). Dual-Process Theories in Social Psychology. New York: Guilford Press.

Durkheim, E. (1952). Suicide, A Study in Sociology. London,: Routledge \& K. Paul.

Elster, J. (1986). Introduction. In J. Elster (Ed.), Rational Choice (pp. 1-33). Washington Square, New York: New York University Press.

Endenburg, G. (1998). Sociocracy: The Organization of Decision-Making. Delft: Eburon.

Farrar, C., Fishkin, J. S., Green, D. P., List, C., Luskin, R. C., \& Paluck, E. L. (2010). Disaggregating Deliberation's Effects: An Experiment within a Deliberative Poll. British Journal of Political Science, 40(2), 333-347.

Gewirth, A. (1978). Reason and Morality. Chicago: University of Chicago Press.

Gilens, M., \& Page, B. I. (2014). Testing Theories of American Politics: Elites, Interest Groups, and Average Citizens. Perspectives on Politics, 12(03), 564-581. http://doi.org/10.1017/S1537592714001595

Hogg, M. A. (1996). Social Identity, Self-Categorization, and the Small Group. In Small Group Processes and Interpersonal Relations (Vol. 2, pp. 227-253). Mahwah, NJ: Lawrence Erlbaum Associates, Inc.

Hogg, M. A., \& Abrams, D. (1999). Social Identity and Social Cognition: Historical Background and Current Trends. In D. Abrams \& M. A. Hogg (Eds.), Social Identity and Social Cognition (pp. xvii, 411). Malden, MA, US: Blackwell Publishers.

Huckfeldt, R. R. (1995). Citizens, Politics, and Social Communication: Information and Influence in an Election Campaign. Cambridge [England]: Cambridge University Press.

Hutchins, E. (1995). How a Cockpit Remembers Its Speeds. Cognitive Science, 19(3), 265-288. http://doi.org/ $10.1207 / \mathrm{s} 15516709 \operatorname{cog} 1903 \_1$

Irwin, A., \& Wynne, B. (2003). Misunderstanding Science?: The Public Reconstruction of Science and Technology. Cambridge University Press.

Kahneman, D., Slovic, P., \& Tversky, A. (1982). Judgment Under Uncertainty: Heuristics and Biases. Cambridge: Cambridge University Press.

Kant, I. (1974). Fundamental Principles of the Metaphysics of Morals. In W. K. Frankena \& J. T. Granrose (Eds.), Introductory Readings in Ethics. Englewood Cliffs, N.J.: Prentice-Hall, Inc.

Koestner, R., Losier, G. F., Vallerand, R. J., \& Carducci, D. (1996). Identified and Introjected Forms of Political Internalization: Extending Self-Determination Theory. Journal of Personality and Social Psychology, 70(5), $1025-1036$. 
Kuhn, T. S. (1996). The Structure of Scientific Revolutions (3rd edition). Chicago, IL: University of Chicago Press.

Lakatos, I., \& Musgrave, A. (Eds.). (1970). Criticism and the Growth of Knowledge. England: Cambridge University Press.

Latour, B. (1993). We Have Never Been Modern. (C. Porter, Trans.). Cambridge, Mass: Harvard University Press.

Lerner, J. S., \& Tetlock, P. E. (1999). Accounting for the Effects of Accountability. Psychological Bulletin, 125(2), 255-275.

Losh, S. C., \& J. O. Nzekwe, B. (2015). Undergraduate Research Engagement Among STEM Majors. The Chemist, 88(1), 13-25.

Luskin, R. C., Fishkin, J. S., \& Jowell, R. (2002). Considered Opinions: Deliberative Polling in Britain. British Journal of Political Science, 32(3), 455-488.

Masci, D. (2009, November 5). Scientists and belief. Retrieved from http://www.pewforum.org/2009/11/05/ scientists-and-belief/

Mayer, J. (2016). Dark Money: The Hidden History of the Billionaires Behind the Rise of the Radical Right. Doubleday.

Mead, G. H. (1962). Mind, Self, and Society: From the Standpoint of a Social Behaviorist. Chicago: The University of Chicago Press.

Mendelberg, T. (2002). The Deliberative Citizen: Theory And Evidence. Political Decision Making, Deliberation and Participation, 6, 151-193.

Mobus, G. E., \& Kalton, M. C. (2015). Principles of Systems Science. New York, NY: Springer New York. Retrieved from http://link.springer.com/10.1007/978-1-4939-1920-8

Muhlberger, P., Stromer-Galley, J., \& Webb, N. (2011). Public Policy and Obstacles to the Virtual Agora: Insights from the Deliberative E-Rulemaking Project. Information Polity, 16(3), 197-214.

Muhlberger, P., \& Weber, L. M. (2006). Lessons from the Virtual Agora Project: The Effects of Agency, Identity, Information, and Deliberation on Political Knowledge. Journal of Public Deliberation (available at Http://services.bepress.com/jpd/), 2(1), 1-39.

National Science Board (NSB). (2014). Science and Engineering Indicators 2014 (No. NSB 14-01). Arlington, VA: National Science Foundation.

National Science Board. (2016). Science and Engineering Indicators 2016, Chapter 7 (No. NSB 16-01). Arlington, VA: National Science Foundation.

Newfield, C. (2011). Unmaking the Public University: The Forty-Year Assault on the Middle Class (Reprint edition). Harvard University Press.

Pierson, P., \& Hacker, J. S. (2010). Winner-Take-All Politics: How Washington Made the Rich Richer--and Turned Its Back on the Middle Class. Simon \& Schuster.

Piketty, T. (2014). Capital in the Twenty-First Century. (A. Goldhammer, Trans.). Harvard University Press.

Pivato, M. J. (2009). Pyramidal Democracy. Journal of Public Deliberation, 5(1), 8.

Readings, B. (1997). The University in Ruins. Harvard University Press.

Robinson, J. P. (1976). Interpersonal Influence in Election Campaigns: Two Step-Flow Hypotheses. The Public Opinion Quarterly, 40(3), 304-319.

Rosenberg, S. W. (2002). The Not So Common Sense: Differences in How People Judge Social and Political Life. New Haven, CT: Yale University Press.

Ryan, R. M. (2000). Self-Determination Theory and the Facilitation of Intrinsic Motivation, Social Development, and Well-Being. American Psychologist, 55.

Ryan, R. M., \& Connell, J. P. (1989). Perceived Locus of Causality and Internalization: Examining Reasons for Acting in Two Domains. Journal of Personality and Social Psychology, 57(5), 749-761.

Simon, H. A. (1969). Sciences of the Artificial. Cambridge, Massachusetts: MIT Press.

Skocpol, T. (2003). Diminished Democracy: From Membership to Management in American Civic Life. Norman: University of Oklahoma Press.

Steele, C. M. (1988). The Psychology of Self-affirmation: Sustaining the Integrity of the Self. In L. Berkowitz (Ed.), Advances in Experimental Social Psychology (Vol. 21, pp. 261-302). 
Street, 1615 L., NW, Washington, S. 800, \& Inquiries, D. 200362024194300 | M. 2024194349 | F. 202419 4372 | M. (2009, November 5). Scientists and Belief. Retrieved from http://www.pewforum.org/ 2009/11/05/scientists-and-belief/

Stryker, S., \& Burke, P. J. (2000). The Past, Present, and Future of an Identity Theory. Social Psychology Quarterly, 63(4), 284-297. http://doi.org/10.2307/2695840

Thagard, P. (2000). Coherence in Thought and Action. Cambridge, Mass.: MIT Press.

Thagard, P., \& Kroon, F. (2006). Hot Thought: Mechanisms and Applications of Emotional Cognition. Cambridge, Mass.: MIT Press.

Troldahl, V. C. (1966). A Field Test of a Modified "Two-Step Flow of Communication" Model. The Public Opinion Quarterly, 30(4), 609-623.

Tyndall Report. (2015). About the Tyndall Report. Retrieved from http://tyndallreport.com/about

Vallacher, R. R., \& Wegner, D. M. (2000). What Do People Think They are Doing? Action Identification and Human Behavior. In E. T. Higgins \& A. W. Kruglanski (Eds.), Motivational science: Social and personality perspectives (pp. 215-228). Philadelphia, PA, US: Psychology Press.

Woolley, A. W., Chabris, C. F., Pentland, A., Hashmi, N., \& Malone, T. W. (2010). Evidence for a Collective Intelligence Factor in the Performance of Human Groups. Science, 330(6004), $686-688$. http://doi.org/10.1126/science.1193147 